\title{
PENDAMPINGAN PENINGKATAN KEPEMIMPINAN DAN PUBLIC SPEAKING ORANG MUDA AMC PU'URERE ENDE
}

\author{
Ana Maria Gadi Djou'), Yosephina Payu Wao'), Konstantinus Denny Pareira Meke ${ }^{3)}$, Josina \\ Irene Brigetha Hutubessy)
}

\author{
1)Program Studi IImu Hukum, Fakultas Hukum, Universitas Flores, Ende, NTT, Indonesia \\ 2) Program Studi Pendidikan Biologi, FKIP, Universitas Flores, Ende NTT, Indonesia \\ 3) Program Studi Pendidikan Matematika, FKIP, Universitas Flores, Ende, NTT, Indonesia \\ ${ }^{3)}$ Program Studi Agroteknologi, Fakultas Pertanian, Universitas Flores, Ende, NTT, Indonesia \\ Corresponding author : Ana Maria Gadi Djou \\ E-mail : emmi.gadidjou12@gmail.com
}

Diterima 29 November 2021, Disetujui 03 Desember 2021

\begin{abstract}
ABSTRAK
Setiap Individu, khususnya orang muda dituntut untuk mampu berkomunikasi dengan baik dan mampu memiliki jiwa leadership guna membangun kehidupannya baik secara pribadi, maupun dalam kehidupan bermasyarakat. Jiwa kepemimpinan dan kemampuan seseorang dalam berbicara merupakan bagian dari komunikasi yang efektif, yaitu mampu merangkul dan merumuskan keputusan untuk mencapai musyawarah yang baik, serta menyampaikan pesan kepada khalayak dengan cara yang tepat dan menarik perhatian. Namun pada kenyataannya, pada Orang Muda yang tergabung dalam komunitas AMC Pu'urere Ende masih belum maksimal dalam memimpin suatu kegiatan serta berbicara didepan umum. Hal ini mendorong tim untuk melakukan pelatihan dan pendampingan kepemimpinan dan public speaking pada Komunitas orang muda di AMC Pu'urere Ende. Tujuan dari program ini adalah untuk membantu orang muda sehingga dapat meningkatkan jiwa kepemimpinan dan rasa percaya diri saat berbicara. Metode yang digunakan dalam kegiatan pengabdian ini adalah ceramah, dialog aktif, diskusi dan rencana tindak lanjut yang digunakan sebagai kegaiatn inti yang ingin dicapai dalam pengabdian ini. Hasil yang didapat dari program ini adalah mampunya Orang Muda AMC Pu'urere dalam mempimpin kegiatan, dari tahap persiapan hingga pelaksanaan, dapat menyusun agenda program tertentu dengan baik dan benar sesuai dengan kebutuhannya, serta memiliki kemampuan public speaking yang memadai.
\end{abstract}

Kata kunci: orang muda; kepemimpinan; public speaking.

\begin{abstract}
Every individual, especially youth people, are required to be able to communicate well and be able to have a leadership spirit, to build his life both personally and in social life. Leadership spirit and one's ability to speak are part of effective communication, namely being able to embrace and formulate decisions to achieve good deliberation, as well as convey messages to audiences in an appropriate and attention-grabbing manner. But in reality, youth who are members of the AMC Pu'urere Ende community are still not optimal in leading activity and speaking in public. This encourages the team to conduct training and mentoring in leadership and public speaking for the youth community at AMC Pu'urere Ende. This program aims to help youth people to improve their leadership spirit and self-confidence when speaking. The methods used in this service activity are lectures, active dialogue, discussions and followup plans which are used as the core activities to be achieved in this service. The results obtained from this program are the ability of AMC Pu'urere Youth People in leading activities, from the preparation stage to implementation, being able to arrange certain program agendas properly and correctly according to their needs and having adequate public speaking skills.
\end{abstract}

Keywords: youth people; leadership; public speaking.

\section{PENDAHULUAN}

Kesuksesan dari suatu lembaga dan suatu organisasi tentu tidak lepas dari sikap kepemimpinan serta kreativitas dari anggotanya (Daswati, 2012). Pemimpin dengan gaya kepemimpinannya dan semua anggota dengan kreativitasnnya tentu mempengaruhi kemajuan dari organisasi atau untuk melaksanakan visi, misi, dan mencapai tujuan organisasi (Esomar \& Sabudun, 2020). Anak Muda Claretian (AMC) Pu'urere Ende, merupakan Komunitas Orang Muda yang didampingi oleh para Misionaris Claretian (CMF). AMC Pu'urere berada di kota Ende, 
Kabupaten Ende, Nusa Tenggara Timur. AMC Pu'urere sendiri selalu terlibat aktif dalam berbagai kegiatan baik gerejani maupun sosial kemasyarkatan baik ditingkat Paroki bahkan kegiatan Internasional.

Orang Muda sebagai suatu organisasi sebagai wadah kreativitas, pengembangan, pengkaderan generasi muda di lingkungan Gereja Katolik. Orang muda sebagai komunitas anak muda harus diberi pembinaan dan pendampingan dalam pelaksanaannya (Dewi, 2018). Salah satu bentuk pembinaan yang selalu digagas yakni membangun jiwa kepemimpinan dan kreativitas orang muda. Pertanyaannya mengapa kepemimpinan menjadi salah satu elemen penting dalam bangunan orang muda (Esomar \& Sabudun, 2020).

Pendampingan menjadi salah satu instrumen penting dari pembinaan OMK karena orang muda diharapkan mampu menjadi generasi yang tangguh, menjadi pembelajar yang mau mengembangkan diri, serta mampu menjadi teladan dalam hidup menggereja dan bermasyarakat (Pratama, Firmanto \& Aluwesia, 2021). Orang muda sebagai agen perubahan tentu saja diharapkan dapat menjadi agen perubahan dalam pemikiran dan dan bertindak sehingga kepemimpinan menjadi salah satu variable yang penting untuk ditumbuhkan dalam diri orang muda (Sjahrifa, 2019). Kepemimpinan menjadi salah satu variabel penting dalam diri orang muda, baik secara individu maupun dalam komunitas. Kepemimpinan adalah bagaimana individu dapat memberikan semangat dan motivasi, bahkan untuk setiap hal kecil dari kegiatan dalam komunitasnya. Kepemimpinan sejatinya adalah tentang kepercayaan dan tanggung jawab (Hidayat, dkk., 2021). Kepemimpinan itu merupakan sebuah seni karena berhubungan dengan talenta dan sekaligus sebagai ilmu karena berhubungan dengan konsep dan gagasan kepemimpinan yang harus dipejari (Silalahi, 2013).

Lebih lanjut orang muda tentunya juga diharapkan dapat menjadi ujung tombak dalam membangun karakter beragama dan bernegara. Karakter ini tidak hanya dilakukan melalui jalur pendidikan saja, tetapi melalui organisasi masyarakat seperti komunitas OMK. Sejumlah kegiatan dalam komunitas ini dapat menjadi sarana untuk mengembangkan kreativitas generasi muda (Kurniasari, dkk., 2016). Salah satunya ialah kemampuan public speaking yang bersifat praktis dan bukan imajinasi, Orang muda dengan kemampuan public speaking yang baik merupakan bekal yang besar untuk dapat membangun komunitas menjadi lebih baik, karena dalam prosesnya terdapat sikap yang mampu merangkul, rasa percaya diri, serta sikap kritis dan empati (Yanuar Herlambang, 2015) (Nurjanah, et, al. 2020). Masyarakat sebagai tempat untuk mengaplikasikan kemampuan dalam berbicara tentu membutuhkan orang muda yang memiliki kematangan intelektual, kreatif, percaya diri, inovatif, memiliki kesetiakawanan sosial dan semangat nasionalisme yang tinggi baik dalam kehidupan beragama, maupun dalam pembangunan nasional (Mulyana, 2020) (Fathoni, Asfahani, Munazatun \& Setiani, 2021). Hal ini menjadikan sikap kreatif diperlukan dalam keanggotaan setiap komunitas, tak terkecuali dalam komunitas OMK sendiri.

Dari teori tersebut, pendampingan terhadap Orang Muda dirasakan sangat penting untuk dilaksanakan. Pendampingan kemudian difokuskan pada sikap kepemimpinan dan kemampuan public spreaking agar dapat menjadi kekuatan besar bagi komunitas dan individu orang muda sendiri. Kegiatan pendampingan difokuskan pada Anak Muda Claretian (AMC) Pu'urere Ende sebagai mitra dalam program pengabdian ini. Orang Muda termasuk didalamnya mereka yang tergabung dalam Anak Muda Claretian diharapkan mampu bersikap profesional dan bertanggungjawab, saat dihadapkan dengan berbagai persoalan internal yang pelik dan rumit (Esomar \& Sadubun, 2020) .

\section{METODE}

Kegiatan Pendampingan terhadap orang muda difokuskan pada Anak Muda Claretian (AMC) Pu'urere Ende. Kegiatan direncanakan dilaksanakan dari Bulan Mei 2021 hingga Agustus tahun 2021. Kegiatan difokuskan pada pemrosesan administrasi kegiatan dan praktek kegiatan selama waktu yang ditentukan tersebut. Metode yang digunakan dalam kegiatan pengabdian ini adalah ceramah, dialog aktif, diskusi dan rencana tindak lanjut yang digunakan sebagai kegaiatn inti yang ingin dicapai dalam pengabdian ini. Kegiatan Pelaksnanan Pelatihan Kepemimpinan Tingkat Dasar terdiri dari beberapa kegiatan pokok yang merupakan bentuk-bentuk latihan dasar kepemimpinan dan kreativitas.

Secara teknis, pelaksanaan kegiatan Pelatihan Kepemimpinan Tingkat Dasar diawali dengan persiapan. Beberapa persiapan yang perlu dilakukan sebelum pelaksanaan kegiatan diantaranya persiapan tempat, sarana dan prasarana serta anggota. Selanjutnya dilakukan pelaksanaan kegiatan yang meliputi kegiatan Pelatihan dan Pendampingan Kepemimpinan. Teknis pelaksanaan terakhir ialah evaluasi 
kegiatan. Evaluasi kegiatan dilakukan daengan melibatkan tim pelaksanan dan tim pendamping AMC Pu'urere. Kegiatan evaluasi ini menjadi perimbangan untuk dilaksanakan kegiatan lanjutan lainnya yang di dalamnya termasuk hubungan kerja sama antara mitra.

\section{HASIL DAN PEMBAHASAN}

Kegiatan pengabdian dibuka dengan perayaan ekaristi bersama OMK AMC Pu'urere, sekaligus diumumkannya kerjasama antara pengabdi dari Universitas Flores dan OMK AMC Pu'urere.

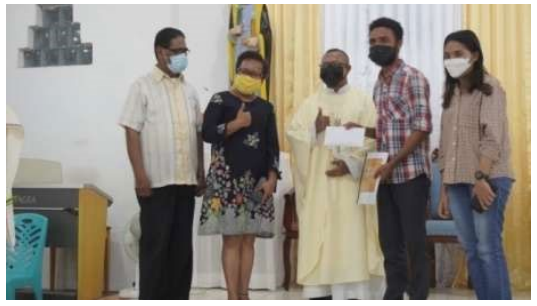

Gambar 1. Perayaan Ekaristi Serta

Penyerahan Proposal Rancangan Kegiatan (Sumber: dok.pribadi).

Perayaan ekaristi sebagai kegiatan pembuka dipilih karena filosofinya sendiri sebagai perayaan keselamatan karena Yesus Kristus mengabdikan dirinya diri dan menjadi teladan bagi umat-Nya, khususnya anak muda katolik (Capah, 2019). Pengumuman jalinan kerjama diselipkan dalam akhir perayaan ekaristi dengan tujuan untuk memanggil para anak muda AMC Pu'urere untuk tinggal dan bersatu dengan Yesus melalui karya pengabdian ini. Pembukaan kegiatan dengan perayaan ekaristi ini juga mengajarkan dan mengajak para orang muda untuk menyikapi bagaiaman mengikuti perayaan ekaristi dengan tetap mengikuti protokol kesehatan di era new normal (Regus \& Tapung, 2020) (Mustofa \& Suhartatik, 2020) (Widyawati, 2021).

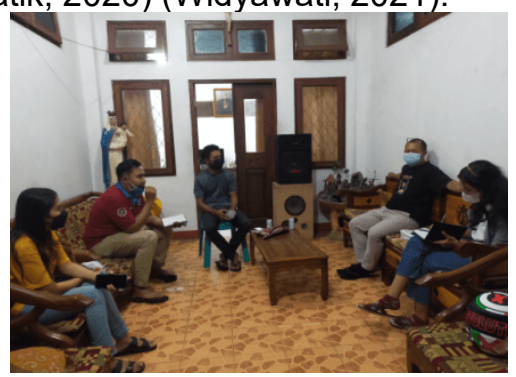

Gambar 2. Diskusi yang dilakukan secara tatap muka langsung (Sumber: dok.pribadi).

Kegiatan pengabdian dilanjutkan dengan persiapan kegiatan bersama antara Pengabdi dari Universitas Flores dan AMC Pu'urere Ende. Kegiatan Persiapan dibagi dalam dua cara yakni online dan ofline. Hal ini menjadi pertimbangan terhadap waktu kerja dan kondisi di era new normal, pelaksanaan kegiatan yang masih dibatasi jumlah kuantitas peserta (Thorik, 2020) (Gunawan, Suranti \& Fathoroni, 2020).

Gambar 2 mennunjukan persiapan kegiatan dilaksanakan secara tatap muka langsung antara tim pengabdi dan orang muda AMC Pu'urere dengan tetap memperhatikan protokol kesehatan (Thorik, 2020). Kegiatan tatap muka ini dibatasi kuantitas personal dan hanya melibatkan tim inti kegiatan pengabdian.

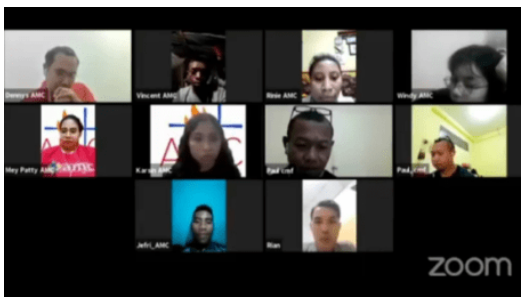

Gambar 3. Persiapan kegiatan dilakukan secara online

(Sumber: dok.pribadi).

Sementara itu untuk persiapan kegiatan pelaksanaan secara online, tim pengabdi maupun AMC Pu'urere Ende menggunakan aplikasi zoom metting untuk mengecek kesiapan dan breffing semua kegiatan.

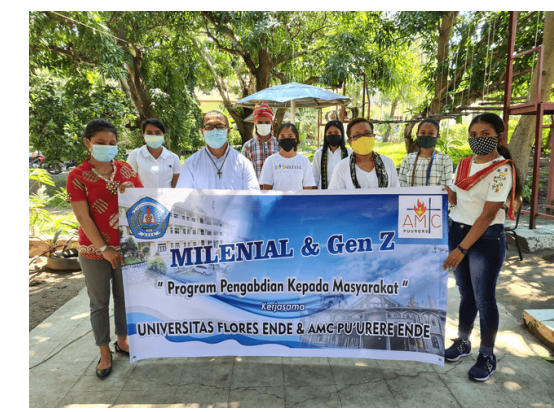

Gambar 4. Foto Bersama Kegaiatan Pengabdian Masyarakat

(Sumber: dok.pribadi).

Gambar 4 menunjukan pelaksanaakn kegiatan inti yang dikemas secara santai dalam bentuk dialog langsung dan diskusi. Kegiatan mengambil umum Milenial dan Gen Z yang merupakan objek dari kegaiatn pengabdian ini. Dialog langsung dikemas secara outdoor menjadi salah satu alternatif yang baik untuk anak muda merasakan rutinitas kebebasan mengembangkan rasa ingin tahu (Sibthorp et al, 2015) (Widiasworo, 2017). Kegiatan dilaksanakan outdoor untuk membuat suasana menjadi lebih santai. Suasana outdoor dipilih untuk mendekatkan anak muda dengan lingkungan sekitar dan bertujuan untuk merubah suasana agar tidak cepat bosan dalam menyimak kegiatan dialog langsung. 
Situasi outdoor membuat Anak Muda Claretian dapat menerima materi dan berdiskusi menjadi lebih menyenangkan serta mampu menciptakan situasi kegiatan yang relatif fleksibel (Seran, Utomo \& Handoyo, 2020). Hal ini berarti bahwa Orang muda lebih leluasa dan merasa diberikan otoritas untuk mengekspresikan imajinasi dan pikiran mereka terhadap materi dalam dialog yang didapatkan berdasarkan pengalaman langsung dilapangan, serta mengaplikasikannya.

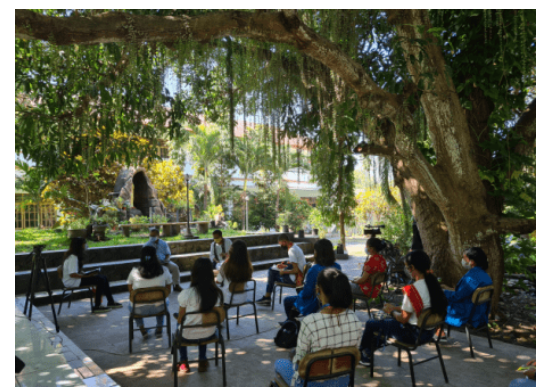

Gambar 5. Kegiatan inti dengan metode dialog langsung

(Sumber: dok.pribadi).

Kegiatan dipimpin oleh moderator dari salah satu anggota AMC Pu'urere sebagai bentuk melatih diri dalam memimpin dialog dan public speaking. Menjadi moderator merupakan salah satu bentuk implementasi dari kegiatan komunikasi yang bisa digunakan dalam kehidupan sehari hari (Ibrahim, et. al, 2018). Oleh karena itu, kemampuan berbicara atau public speaking dapat diasah salah satunya menjadi moderator dalam kegiata organsisasi kecil yang ada di lingkungan masyarakat (Zakrimal, Purwanti \& Aziz, 2020). Dialog langsung dikemas lebih ringan dan santai menyesuaikan dengan kondisi audiens yang merupakan anak muda, sehingga terkesan lebih dapat membaur dan mempengaruhi moderator agar lebih percaya diri (Girsang, 2018) (Tamelab, Ngongo \& Oetpah, 2021).

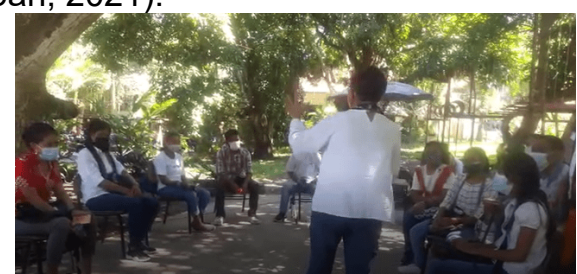

Gambar 5. Kegiatan inti dengan metode Kelompok

(Sumber: dok.pribadi).

Gambar 6 menunjukan bahwa kegiatan dialog langsung juga dikemas dalam bentuk diskusi kelompok yang menitikberatkan pada rancangan kegiatan selanjutnya sebagai bentuk rencana tidak lanjut. Masing-masing peserta menyampaikan rencana kegiatannya sekaligus melatih public speaking serta mengorganisasikan perencanaan lebih konkrit dan beruntun dalam penyampaiannya. Hal ini bertujuan bahwa kagiatan pengabdian mengajak orang muda untuk tidak hanya terfokus pada pentransferan ilmu melainkan juga melalui latihan dan praktek secara kontinyu melalui rencana tindak lanjut (Dewi, 2018) (Hardjono, 2020) (Nurjanah, et, al. 2020)

Lebih lanjut dalam rencana tindak lanjut dari kegiatan pelatihan kepemimpinan dan public speaking ini, komunitas Orang Muda AMC Pu'urere Ende melaksanakan banyak kegiatan diantaranya bakti sosial sebagai bentuk kepedulian terhadap sekitar dan pendalaman dan sharing kitab suci melalui video pendek yang disebut Mutiara sabda AMC.

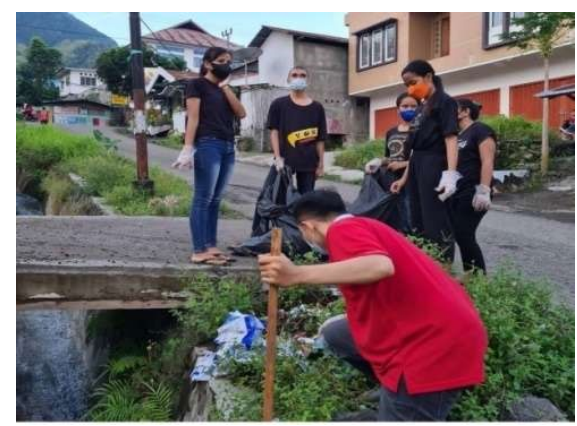

Gambar 7. Kegiatan tindak lanjut dalam bentuk bakti sosial

(Sumber: dok.pribadi).

Dalam setiap kegiatan bakti sosial, selalu dibentuk tim panitia kecil guna melatih para orang muda untuk mampu melatih manajemen kepemimpinan dalam setiap pertemuan dan merancang kegiatan sebelum pelaksanaan (Ibrahim, et. al, 2018). Bakti sosial juga menjadi sarana kepemimpinan sebagai bentuk kepedulian individu dalam bersikap terhadap lingkungan dan sekitarnya (Susilo, et. al., 2021) (Wati, et. al., 2020).

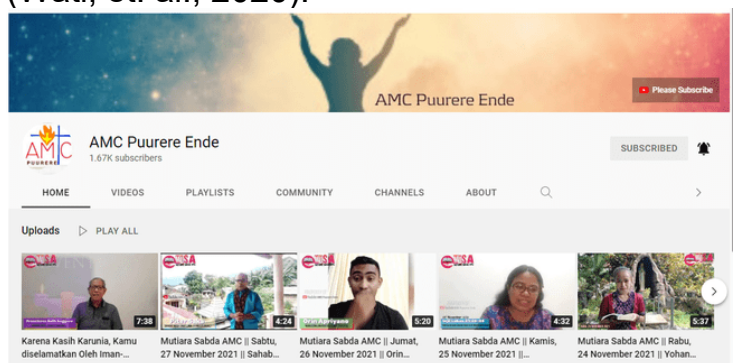

Gambar 8. Kegiatan tindak lanjut dalam bentuk Video Pendalaman Kitab Suci (Sumber: dok.pribadi)

Lebih lanjut dalam gambar 8, kegiatan tindak lanjut berikutnya ialah pendalaman dan sharing kitab suci melalui video pendek yang disebut Mutiara sabda AMC. Video pendek 
dipilih sebagai media sharing yang pas dimasa pandemic covid 19 ini. Semua video pendalamn kitab suci dilakukan dan dishare pada laman youtube AMC Pu'urere Ende. Hal ini sebagai bentuk aplikasi orang muda dalam mendalami kitab suci dan juga kemampuan mereka dalam public speaking (Batrinca, et. al., 2013) (Mambu, Wahyudi \& Posumah, 2018). Hal ini dimaksudkan agar orang muda dapat belajar secara mandiri sehingga berdampak langsung maupun tidak langsung terhadap peningkatan rasa percaya dirinya dan perkembangan kemampuan dalam public speaking mereka. Berlatih public speaking dalam perekaman video melatih orang muda untuk memiliki banyak kesempatan untuk mampu mempengaruhi audiensnya antara lain dengan storytelling (bercerita), body language (bahasa tubuh), tone of voice (nada suara), pauses (jeda), visual cues atau menggunakan isyarat visual (Octavianti \& Rusdi, 2019).

Maanfaat melatih public speaking bagi pemuda juga untuk meningkatkan kemampuan komunikasi, meningkatkan kemampuan organisasi, membantu mengontrol emosi, meningkatkan memori, meningkatkan kepercayaan diri dan sebagai bekal untuk kehidupan mendatang (Fathoni, Asfahani, Munazatun \& Setiani, 2021). Public speaking dilatih secara terus menerus guna mencapai tingkat efektif. Berbicara depan kameramampu mengurangi rasa gugup karena tidak adanya audiens yang mendengar. Hal ini membantu orang muda untuk dapat menumbuhkan rasa percaya dirinya ketika berbicara di depan banyak orang (Sudarmono, Apuanor \& Utami, 2018) (Hartini \& Chumaeson, 2021).

\section{SIMPULAN DAN SARAN}

Kegiatan pengabdian masyarakat bersama orang muda di komunitas AMC Pu'urere Ende dapat dilaksanakan dengan baik dan mampu memberikan manfaat dan menghasilkan rencana tindak lanjut yang maksimal. Orang muda mampu membangun sikap kepemimpinan yang baik melalui berbagai kegiatan yang dilaksanakan. Sikap berani mengambil keputusan melalui musyawarah, rasa peduli dengan lingkungan dibangun melalui kegiatan pelatihan dan dilanjutkan dengan rencana tindak lanjut dalam bentuk kegiatan bakti sosial. Rasa percaya diri dalam berbicara dengan baik juga turut efektif melalui kegiatan pelatihan public speaking, ditambah lagi rencana tindak lanjut berupa pendalaman kitab suci memalui video mutiara sabda. Kegiatan ini diharapkan mampu membekali orang muda khusunya AMC Pu'urere Ende, untuk terus mengasah kemampuan mereka sebagai individu yang berkompeten dan berguna bagi masyarakat,

\section{UCAPAN TERIMAKASIH}

Tim penulis sekaligus pengabdi mengucapkan terima kasih kepada Yayasan Perguruan Tinggi Flores, Universitas Flores, Lembaga Penelitian dan Pengabdian Masyarakat (LP2M) Universitas Flores dan AMC Pu'urere Ende. Dukungan baik berupa materil dan moril sangat membantu tim pengabdi dalam menjalankan kegiatan ini dengan lancar.

\section{DAFTAR RUJUKAN}

Alfonsius Yoga Pratama, Antonius Denny Firmanto, \& Nanik Wijiyati Aluwesia. (2021). Urgensitas Pembinaan Orang Muda Katolik terhadap Bahaya Krisis Identitas. VOCAT: JURNAL PENDIDIKAN KATOLIK, 1(2), 68 - 78. https://doi.org/10.52075/vctjpk.v1i2.22

Batrinca L., Stratou G., Shapiro A., Morency LP., Scherer S. (2013) Cicero Towards a Multimodal Virtual Audience Platform for Public Speaking Training. In: Aylett R., Krenn B., Pelachaud C., Shimodaira $\mathrm{H}$. (eds) Intelligent Virtual Agents. IVA 2013. Lecture Notes in Computer Science, vol 8108. Springer, Berlin, Heidelberg. https://doi.org/10.1007/978-3-64240415-3 10

Viktorahadi, R.F. Bhanu. (2021). Perubahan Pola Sakramen Umat Katolik Bandung Pada Era Pandemi Covid19. Temali: Jurnal Pembangunan Sosial. Volume 4, Nomor 1: 72-79. 10.15575/jt.v4i1.12310

Capah, S. R. (2019). Narsisisme Para Imam dalam Perayaan Ekaristi Suci. Studia Philosophica et Theologica. 19(2), 144-167

Daswati Daswati. (2012). Implementasi Peran Kepemimpinan Dengan Gaya Kepemimpinan Menuju Kesuksesan Organisasi. Academica. 4(1), 783798

Dewi, F. I. R. (2018). Peningkatan Kapasitas Orang Muda Katolik (OMK) yang Tangguh dalam Berkarya. Prosiding Seminar Hasil Pengabdian Kepada Masyarakat, 1, 1-6

Dewi, D. P. (2018). Asesmen Sebagai Upaya Tindak Lanjut Kegiatan Identifikasi Terhadap Anak Berkebutuhan Khusus. Wahana. 70(1), 17-24. https://doi.org/10.36456/wahana.v70i 1.1563 
Esomar, M. J., \& Sadubun, V. L. A. . (2020). Membangun Jiwa Kepemimpinan yang Berintegritas dan Inovatif Melalui Pelatihan Kepemimpinan di Kalangan Orang Muda Katolik Ambon. Jurnal Abdidas, 1(6), 616-624. https://doi.org/10.31004/abdidas.v1i6 .138

Fathoni, T., Asfahani, A., Munazatun, E., \& Setiani, L. (2021). Upaya Peningkatan Kemampuan Public Speaking Pemuda Sragi Ponorogo. Amalee: Indonesian Journal of Community Research and Engagement, 2(1), 2332.

https://doi.org/10.37680/amalee.v2i1. $\underline{581}$

Girsang, L. R. M. (2018). 'PUBLIC SPEAKING' SEBAGAI BAGIAN DARI KOMUNIKASI EFEKTIF (KEGIATAN PKM di SMA KRISTOFORUS 2, JAKARTA BARAT). Jurnal Pengabdian dan Kewirausahaan, 2(2), 81-85.

http://dx.doi.org/10.30813/jpk.v2i2.13 59

Gunawan, G., Suranti, N. M. Y., \& Fathoroni, F. (2020). Variations of Models and Learning Platforms for Prospective Teachers During the COVID-19 Pandemic Period. Indonesian Journal of Teacher Education, 1(2), 61-70. Retrieved from https://journal.publication-

center.com/index.php/ijte/article/view/ 95

Hardjono, W. (2020). ANALISIS EFEKTIVITAS RENCANA TINDAK LANJUT PESERTA PELATIHAN PERTANIAN. AgriWidya. 1(10), 119-127

Hartini, S., \& Chumaeson, W. (2021). Peningkatan Rasa Percaya Diri Melaui Pelatihan Public Speaking pada Siswa SMK N I Selo Boyolali. SENYUM BOYOLALI, 2(1), 33-39. https://doi.org/10.36596/sb.v2i1.572

Hidayat, A., dkk. (2021). Pelatihan Dasar Kepemimpinan Taman Belajar Kreatif Mekarsari. Jurnal PADMA: Pengabdian Dharma Masyarakat, 1(1), 72-75

Ibrahim, et. al. (2018). PENINGKATAN KUALITAS SUMBER DAYA MANUSIA PEMUDA PESISIR MELALUI PELATIHAN MANAJEMEN KEPEMIMPINAN DI KECAMATAN POTO TANO KABUPATEN SUMBAWA BARAT. Selaparang: Jurnal Pengabdian Masyarakat
Volume 5, Nomor 1, Desember 2021.

p-ISSN : 2614-5251

e-ISSN : 2614-526X

Berkemajuan. 2(1), 43-47. https://doi.org/10.31764/jpmb.v2i1.56 5

Kurniasari, D., dkk. (2016). Peranan Organisasi Karang Taruna dalam Mengembangkan Kreativitas Generasi Muda di Desa Ngembalrejo. Unnes Civic Education Journal. 2(2), 77-82

Mambu, J. Y., Wahyudi, A. K. \& Posumah, F. (2018). APLIKASI SIMULASI PUBLIC SPEAKING BERBASIS VIRTUAL REALITY. Cogito Smart Journal. 4(2). 327-336.

http://dx.doi.org/10.31154/cogito.v4i2 $.139 .327-336$

Mulyana, Y. (2020, March 21). Peran Sumber Daya Manusia (SDM) / Generasi Muda Dalam Menyongsong Revolusi Industri 4.0. PRISMAKOM, 16(1), 3646.

https://doi.org/https://doi.org/10.2301 600/prismakom.v16i1.41

Mustofa, A. \& Suhartatik, N. (2020). MENINGKATKAN IMUNITAS TUBUH DALAM MENGHADAPI PANDEMI COVID-19 DI KARANGTARUNA KEDUNGGUPIT, SIDUHARJO, WONOGIRI, JAWA TENGAH. Selaparang: Jurnal Pengabdian Masyarakat Berkemajuan. 4(1), 317323,

https://doi.org/10.31764/jpmb.v4i1.31 00

Nurjanah, V., et. al. (2020. PELATIHAN KEPEMIMPINAN BIDANG KETRAMPILAN PUBLIC SPEAKING, SURVIVAL, CHARACTER BUILDING, DAN COMMUNITY BUILDING BAGI KEBIDELAN SEMINARI ST. PAULUS PALEMBANG. JMM: Jurnal Masyarakat Mandiri. 4(1). 43-54. https://doi.org/10.31764/jmm.v4i1.17 04

Oktavianti, R. \& Rusdi, F. (2019) BELAJAR PUBLIC SPEAKING SEBAGAI KOMUNIKASI YANG EFEKTIF. Jurnal Bakti Masyarakat Indonesia. 2(1) $117-122$

Regus, M. \& Tapung, M. M. (2020). Penanganan Covid-19 dalam Semangat Diakonia Gereja Keuskupan Ruteng. Jurnal Pendidikan Dan Pengabdian Masyarakat, 2(May), 41-52. https://doi.org/10.36407/berdaya.v2i2 .175

Seran, W. A., Utomo, D. H. \& Budi Handoyo, B. (2020). Pengaruh Model Pembelajaran Outdoor Study 
Berbantuan Video Conference terhadap Kemampuan Menulis Karya IImiah Mahasiswa. Jurnal Pendidikan: Teori, Penelitian, dan Pengembangan, 5(2), 142-152. http://dx.doi.org/10.17977/jptpp.v5i2. 13157

Sibthorp, J., Collins, R., Rathunde, K., Paisley,K., Schumann, S., Pohja, M., \& Baynes, S. (2015). Fostering Experiential Self-Regulation Through Outdoor Adventure Education. Journal of Experiential Education, 38(1), 26-40. https://doi.org/10.1177/10538259135 16735

Silalahi, T.B., (2013). Pemimpin Masa Depan. Tanpa Kota Penerbit: Pena Semesta.

Sjahrifa, C. (2019). Pelatihan "Leadership And Coaching" Untuk Meningkatkan Kemampuan Para Calon Pengajar Muda Dalam Program Indonesia Mengajar. Journal of Sustainable Community Development (JSCD). 1(1), 18- 23

Sudarmono, S., Apuanor, A. \& Eva Utami, E. (2018). TINGKAT KEPERCAYAAN DIRI MAHASISWA DITINJAU DARI PUBLIC SPEAKING. Jurnal Paedagogie. 6(2). 71-78. https://doi.org/10.46822/paedagogie. v6i2.112

Susilo, et., al. (2021). KEGIATAN BERSAMA BAKTI SOSIAL DALAM RANGKA PELESTARIAN LINGKUNGAN HIDUP, PENYULUHAN MASYARAKAT DAN AKSI NYATA PEMBERSIHAN SAMPAH PLASTIK DI OBJEK WISATA PANTAI KETAM. Jurnal Awam. 2(1), 32-38

Tamelab, P., Ngongo, M. H. L., \& Oetpah, D. (2021). MENINGKATKAN KEPERCAYAAN DIRI MAHASISWA DALAM KEMAMPUAN PUBLIC SPEAKING DI SEKOLAH TINGGI PASTORAL KEUSKUPAN AGUNG KUPANG. Selidik (Jurnal Seputar Penelitian Pendidikan Keagamaan), 2(1), 54-63. Retrieved from

http://www.ejurnal.org/index.php/selid ik/article/view/38

Thorik, S. H. (2020). Efektivitas Pembatasan Sosial Berskala Besar Di Indonesia Dalam Penanggulangan Pandemi Covid-19. Adalah: Buletin Hukum dan Keadilan 4(1), 115-120. https://doi.org/10.15408/adalah.v4i1. 15506
Wati, F., Aje, A. U., Nande, M., \& Beda, E. (2020). BAKTI SOSIAL PEMBERSIHAN LINGKUNGAN MASJID JAMI' AT-TAQWA ONEKORE DALAM RANGKA PANCA WINDU UNIVERSITAS FLORES KE-40 TAHUN 2020. Mitra Mahajana: Jurnal Pengabdian Masyarakat, 1(1), 11-19. https://doi.org/10.37478/mahajana.v1 i1.713

Widiasworo, E.(2017). Strategi dan Metode Mengajar Siswa di Luar Kelas (outdoor learning) Secara Aktif, Kreatif, Inspiratif, \&Komunikatif. Yogyakarta: AR-RUZZ Media.

Widyawati, F. (2021). Peran Tim Gugus Tugas COVID-19 Paroki Dalam Memenuhi Hak Ibadah di Paroki Santu Mikael, Keuskupan Ruteng. Jurnal SOLMA, 10(1), 110-120. https://doi.org/10.22236/solma.v10i1. $\underline{5494}$

Yanuar Herlambang, S.Sn., ACA. (2015). PERAN KREATIVITAS GENERASI MUDA DALAM INDUSTRI KREATIF TERHADAP KEMAJUAN BANGSA. Tematik : Jurnal Teknologi Informasi Komunikasi (e-Journal), 2(1), 61-71. https://doi.org/10.38204/tematik.v2i1. 66

Zakrimal, Z., Purwanti, A., \& Aziz, R. M. (2020). PEMBINAAN HOW TO BE OUTSTANDING MC AND MODERATOR DI KARANG TARUNA GARUDA VILLA HANG LEKIR BATAM. PUAN INDONESIA, 1(2), 59-64. https://doi.org/10.37296/about.v1i2.1 $\underline{3}$ 